\title{
Basaloid carcinoma of the anal canal
}

\author{
LILliAN S. C. PANG AND B. C. MORSON
}

From the Research Department, St. Mark's Hospital, London

SYNOPSIS The pathology and results of treatment of 36 cases of basaloid carcinomas of the anal canal are described. This variant of squamous cell carcinoma of the anal region arises from the entodermal-ectodermal junctional zone of the anal canal at or above the dentate line. Basaloid carcinomas have histological characteristics which resemble basal cell carcinoma of the skin, in particular the presence of palisading of the nuclei at the periphery of the clumps of tumour cells, but are potentially metastasizing tumours. They have been subdivided into three grades of malignancy, namely, well-differentiated, moderately differentiated, and anaplastic basaloid carcinoma. It has been shown that cases of well-differentiated and moderately differentiated basaloids have a good prognosis even when lymph node metastasis has already taken place. Those of anaplastic basaloid carcinoma have a very poor prognosis even in the absence of lymphatic metastases.

The term 'basaloid' was used by Wittoesch, Woolner, and Jackman (1957) to describe certain tumours of the anal canal which showed a histological resemblance to basal cell carcinoma of the skin. In 1960, Lone, Berg, and Stearns found that these basaloid carcinomas had a better prognosis than other squamous cell carcinomas of the anal canal. The object of this paper is to describe the pathology and results of treatment of 36 cases of basaloid carcinoma of the anal canal seen at St. Mark's Hospital during the years 1928-64.

\section{MATERIAL AND METHODS}

This study is part of a review of all malignant tumours of the anal canal, some results of which have been reported in previous papers (Morson 1960; Morson and Volkstadt, $1963 \mathrm{a}$ and b). The basaloid tumours were identified among 206 carcinomas of the anal canal and anal margin seen at St. Mark's Hospital during the period 1928-64. Malignant melanoma, muco-epidermoid carcinoma, adenocarcinoma of the anal canal, and true basal cell carcinoma of the peri-anal skin were excluded.

In those patients treated by excision of the rectum the surgical specimens were prepared by cutting along the anterior aspect and stretching them out on a metal frame. The specimens were all photographed and the extent of spread assessed by anatomical dissection and microscopy. Because of this routine method it has been possible to locate the site of origin of most of the tumours. In particular the relationship of the tumour to the dentate line of the anal canal was recorded.

Received for publication 1 September 1966.

\section{INCIDENCE}

Thirty-six basaloid carcinomas were identified among 206 cases of squamous cell carcinoma of the anus and anal canal (18\%). If anal margin tumours are excluded then the incidence rises to $26 \%$. There were 17 males and 19 females. The ages of patients varied from 41 to 80 , the average being 60 years. The mean ages for males and females were not significantly different.

\section{SITE OF ORIGIN}

Accurate records of the exact location of the tumours within the anal canal were available for 33 of the 36 cases. In 23 the tumour was located entirely above the line of the anal valves (dentate line). Of the other 10 cases, six were located mainly above and four astride the dentate line. No quadrant of the anal canal was particularly affected.

\section{HISTOLOGY}

The feature which most distinguishes basaloid carcinoma from other squamous cell tumours of $\varphi$ the anal canal is the presence of palisading at the periphery of the clumps of tumour cells (Figs. 1 and 2). The appearance has some resemblance to the palisading seen in basal cell carcinoma or rodent ulcer of the skin. Moreover, a tendency to form solid, circumscribed clumps of tumour cells containing small, round, or ovoid nuclei which are regular in shape and size (Fig. 3 ) is also reminiscent 
of rodent ulcer. Other features suggestive of basal cell carcinoma include a prominent pseudo-acinar pattern (Fig. 2), which is really a manifestation of palisading and was seen in three cases. The formation of concentric whorls of squamoid cells (Figs. 4 and 9) in some cases gave the impression of incomplete keratinization. In five cases there were small, sharply defined pearls of keratin scattered in small numbers throughout the tumours. In one case the tumour cells showed a patchy tendency to form small acini, some of which contained very small quantities of mucin. In others the clumps of tumour tended to break up to form irregular columns of cells.

One feature of the histology unlike basal cell carcinoma was the presence of a varying amount of eosinophilic necrosis within the clumps cf tumour cells (Fig. 6). This was a prominent feature in 14 of the 37 cases. In four of these tumours it was present in considerable quantity in the middle of the clumps of tumour, the cells being restricted to a narrow rim around the periphery. It was possible to find what appeared to be keratin plugs among the otherwise structureless masses of eosinophilic material.

Other features unlike basal cell carcinoma included the presence of some variation in the shape and size of nuclei (Figs. 7 and 8), including giant forms, particularly in those cases regarded as anaplastic basaloid. The growing edge of our basaloid tumours has shown clear signs of a much greater degree of invasiveness than is usually seen in rodent ulcer. In a few cases there was a tendency to a papillary growth pattern resembling transitional cell carcinoma of the bladder.

It must be emphasized that basaloid carcinomas of the anal canal are not a rigidly exclusive group. Their histology is purely or, at least, predominantly basaloid, but here and there features of squamous cell carcinoma may be present. In our experience other squamous cell carcinomas of the anal canal may show occasional small patches of basaloid structure, but these have not been included in the present series of cases. Similarly we have seen a few anal canal cancers without a basaloid appearance which have contained the eosinophilic necrosis mentioned above.

The 36 tumours were divided into three groups according to the amount of palisading and the extent to which they retained their capacity to form circumscribed clumps of cells. Other features such as the appearance of the nuclei and the amount of eosinophilic necrosis were also taken into account in the histological assessment of their malignancy.

GROUP I: WELL-DIFFERENTIATED BASALOID CARCINOMA (FIGS. 1-3) There were 10 cases in group I. Palisading was present throughout and the tumour cells formed circumscribed clumps. The nuclei were regular in size and shape and mitoses were few. All cases showed some eosinophilic necrosis but only in small amounts.

GROUP II: MODERATELY DIFFERENTIATED BASALOID CARCINOMA (FIGS. 4 AND 5) There were 12 cases in group II. Palisading was patchy and less prominent. Clumping of tumour cells was still present but not quite so circumscribed as in group I. The nuclei tended to be larger but were regular in size and shape. The number of mitoses was greater than in group I. There was a greater amount of eosinophilic necrosis than in group I, although it was completely absent in one tumour. In another it was extensive.

GROUP III: POORLY DIFFERENTIATED AND ANAPLASTIC BASALOID CARCINOMA (FIGS. 6-9) There were 14 cases in group III. Palisading was absent. Clumping of tumour cells was absent in five cases but was present in the other nine although the clumps were breaking up into irregular columns of cells. The nuclei showed variation in size and shape, were very hyperchromatic and there were many mitoses. Eosinophilic necrosis was a prominent feature in seven of the 14 cases, present in small amounts in four cases, and absent in three tumours. In five cases the appearances were particularly anaplastic and resembled the 'basaloid small cell' carcinoma of Wittoesch et al. (1957).

It is true that these anaplastic basaloid carcinomas have only a very superficial resemblance to basal cell carcinoma. However, they are distinctive and quite unlike other anaplastic squamous cell tumours of the anal region.

HISTOGENESIS In some of the pathological specimens studied, there has been evidence of the histogenesis of basaloid carcinomas of the anal canal. Zones of transition between invasive tumour and changes of a pre-invasive type suggest that basaloid carcinoma arises from the basal cells of stratified non-keratinizing squamous epithelium and from a type which is morphologically intermediate between stratified squamous and transitional cell epithelium.

\section{LYMPHATIC SPREAD}

Six of the 36 cases received no surgical treatment because of advanced disease, and three were treated by local excision. One of these had involvement of inguinal nodes. Of the remaining 27 patients treated by excision of the rectum and anal region, $14(52 \%)$ had involvement of the regional lymphatic glands. Eight of these had haemorrhoidal nodes only involved; four had both haemorrhoidal and inguinal 


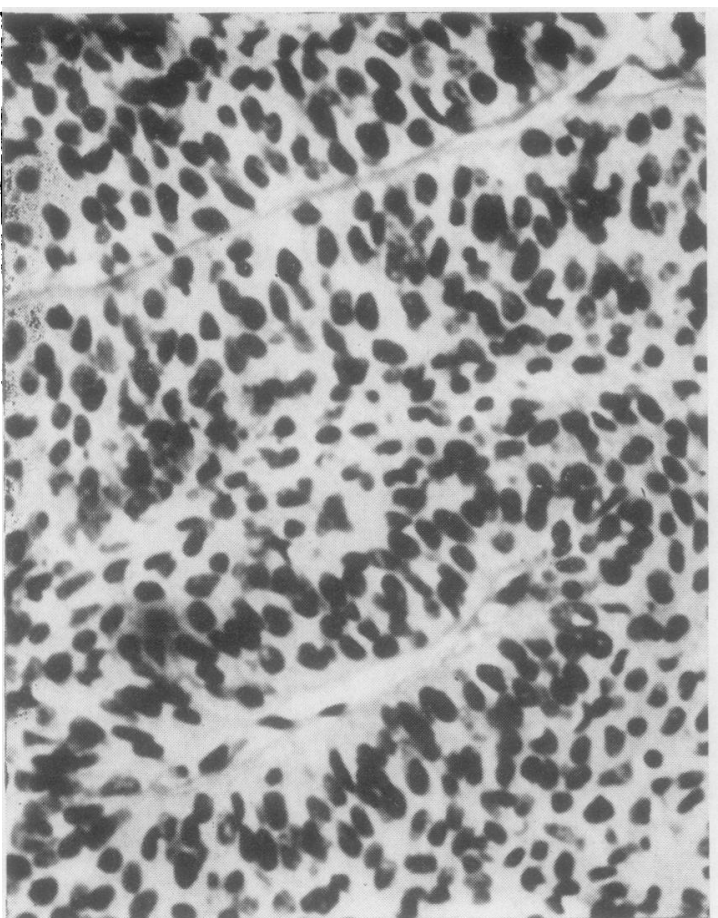

FIG. 1 .

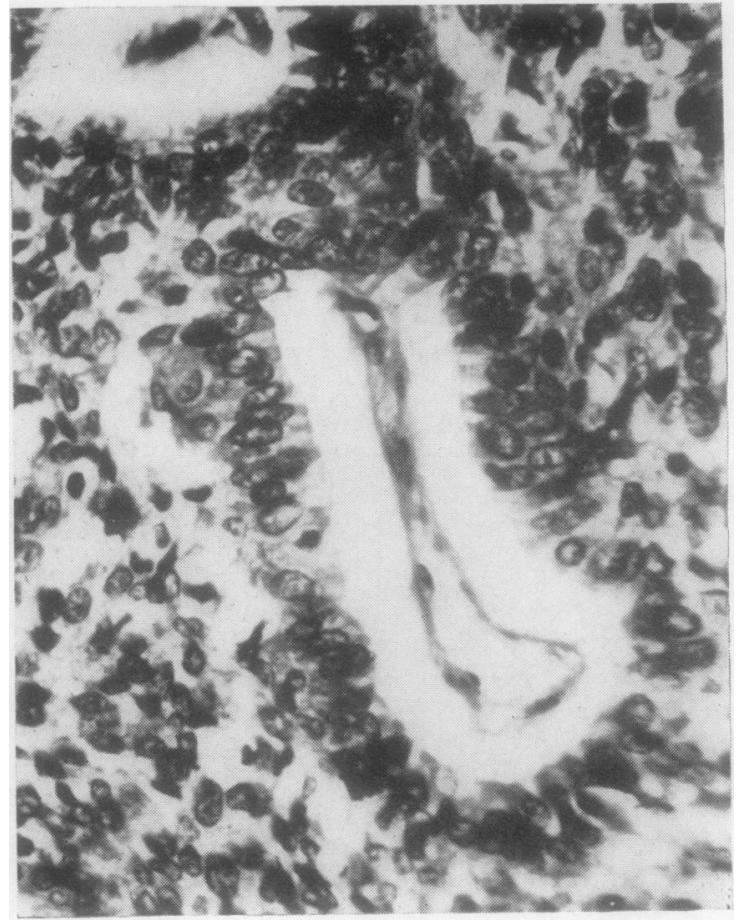

FIG. 2.

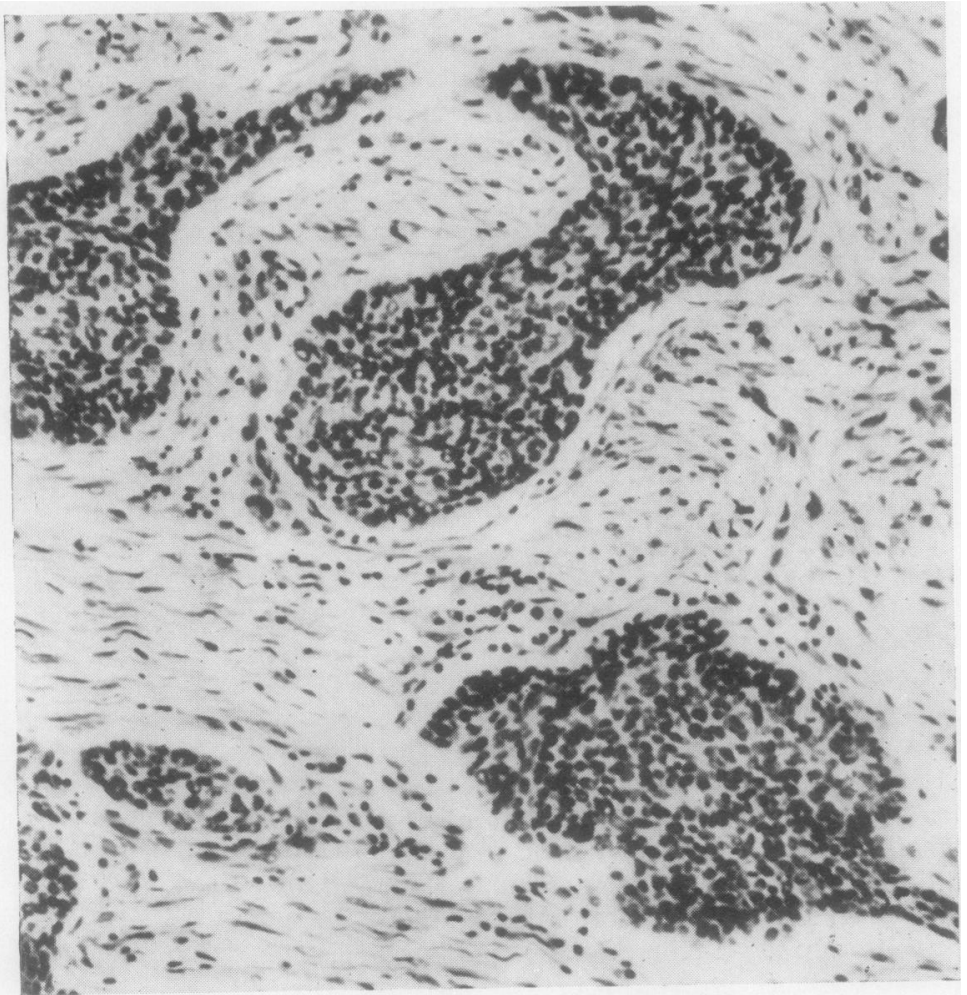

FIG. 1. Well-differentiated basaloid carcinoma. There is palisading of nuclei at the periphery of circumscribed clumps of tumour cells, the nuclei of which are regular in shape and size. Haematoxylin and eosin $\times 100$.

FIG. 2. Well-differentiated basaloid carcinoma showing palisading of nuclei giving a pseudo-acinar pattern. The cells are uniform in shape and size. Haematoxylin and eosin $\times 125$.

FIG. 3. Well-differentiated basaloid carcinoma showing solid circumscribed clumps of tumour cells with small round or ovoid nuclei which are regular in shape and size. Haematoxylin and eosin $\times 100$.

FIG. 3. 


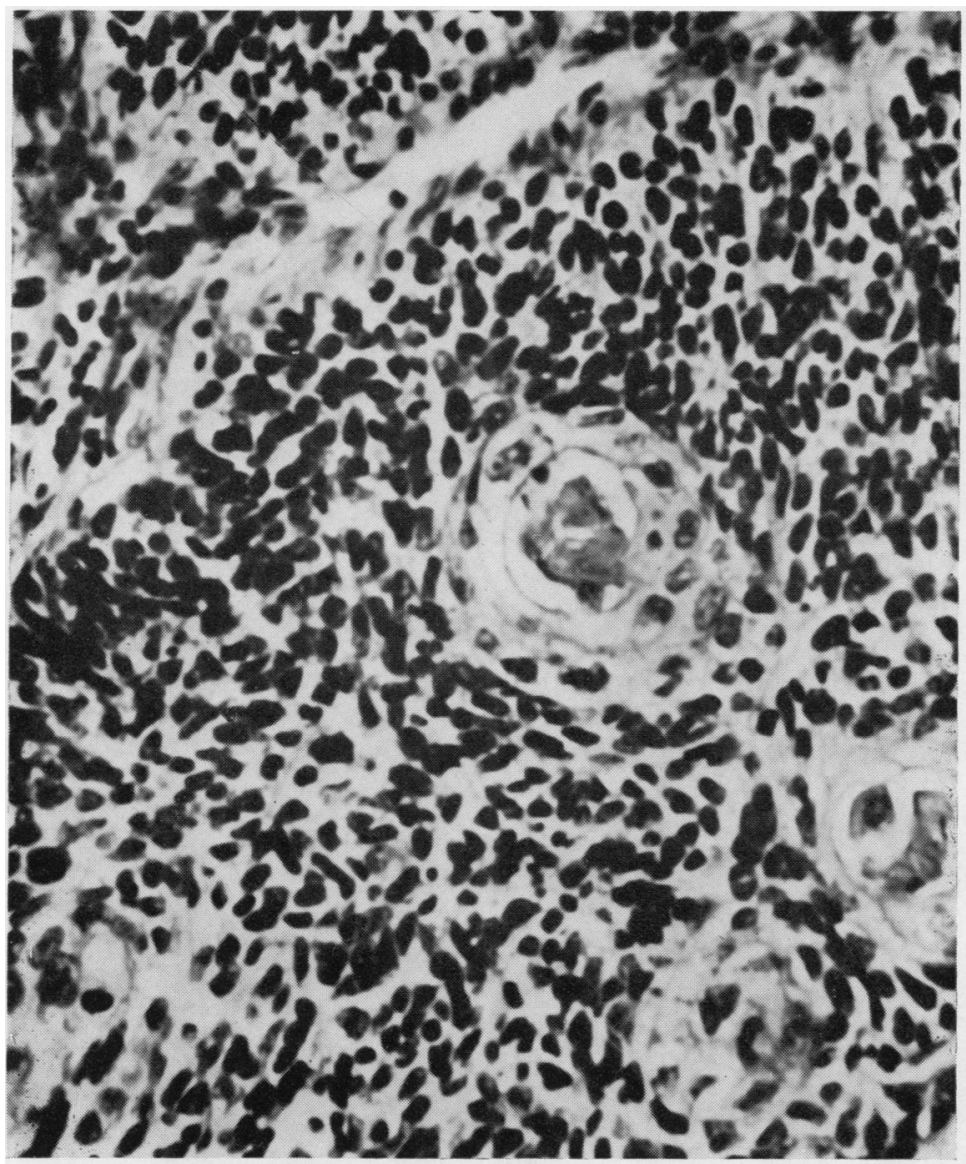

FIG. 4. Moderately differentiated basaloid carcinoma. The nuclei are regular in size and shape but there is only a slight tendency to palisading of nuclei. The concentric whorls of squamous cells in the right-hand side of the photograph give the impression of incomplete keratinization.

Haematoxylin and eosin $\times 300$.

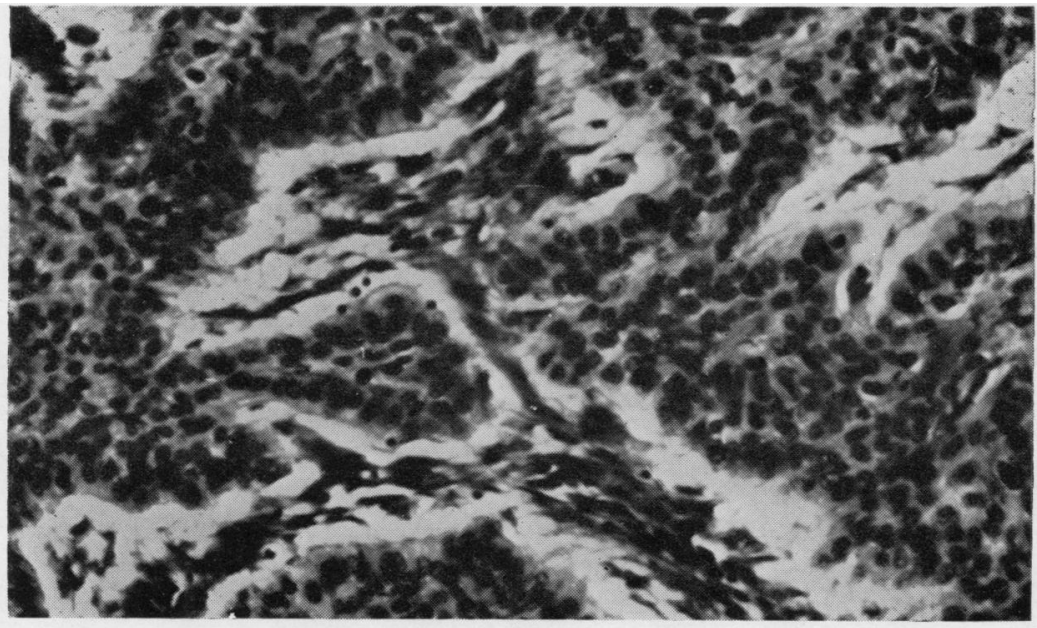

FIG. 5. Moderately

differentiated basaloid

carcinoma. There is a slight tendency to palisading and the tumour cells are arranged in solid circumscribed clumps. The nuclei are regular in size and shape. Haematoxylin and eosin $\times 100$. 


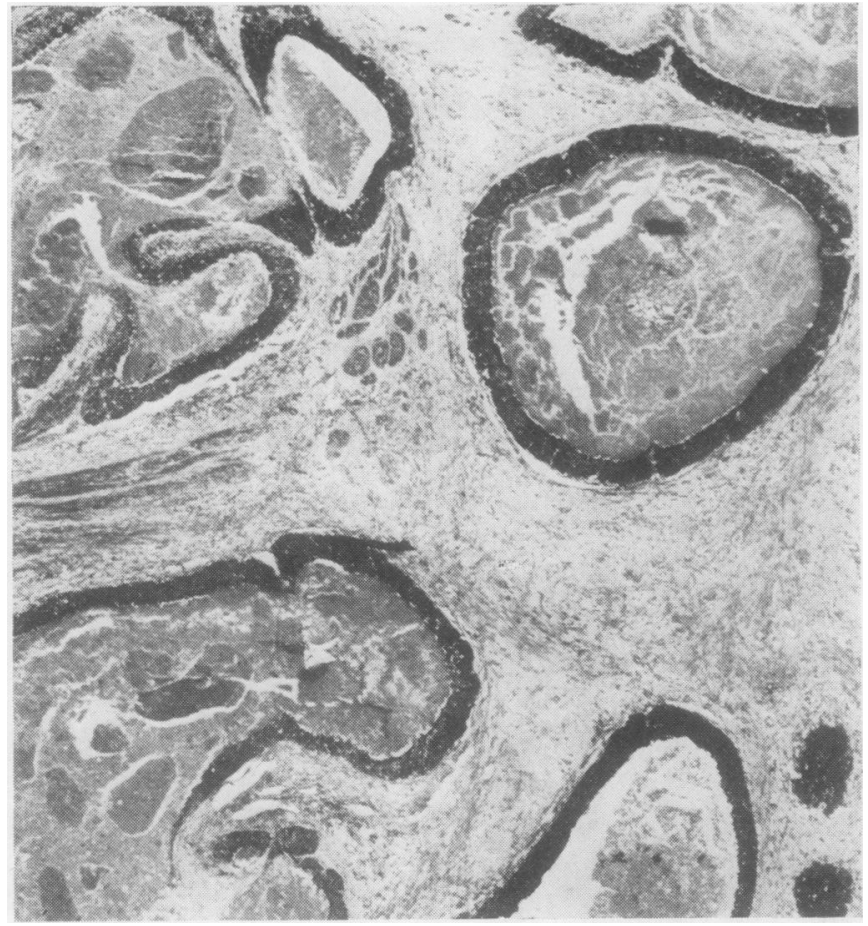

FIG. 6. Poorly differentiated basaloid carcinoma. There is extensive eosinophilic necrosis in the centre of clumps of tumour, the cells being restricted to a narrow rim around the periphery. Haematoxylin and $\operatorname{eosin} \times 34$.

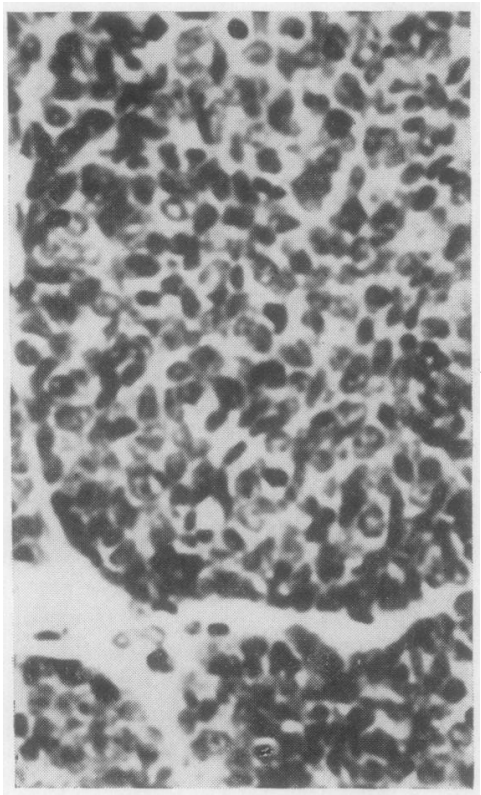

FIG. 7. Poorly differentiated basaloid carcinoma. There is clumping of tumour cells but palisading is absent. Haematoxylin and eosin $\times 300$.

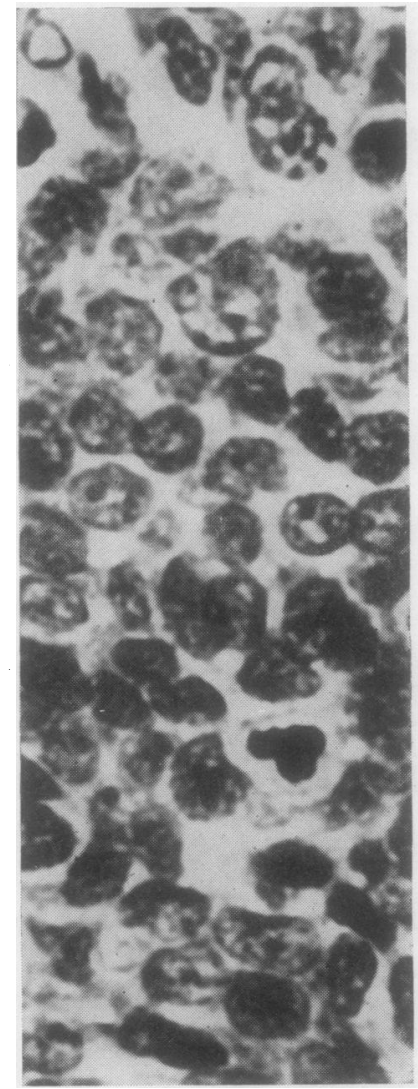

FIG. 8. Poorly differentiated basaloid carcinoma. Highpower view of Fig. 7 to show anaplastic features.

Haematoxylin and eosin $\times 425$. 


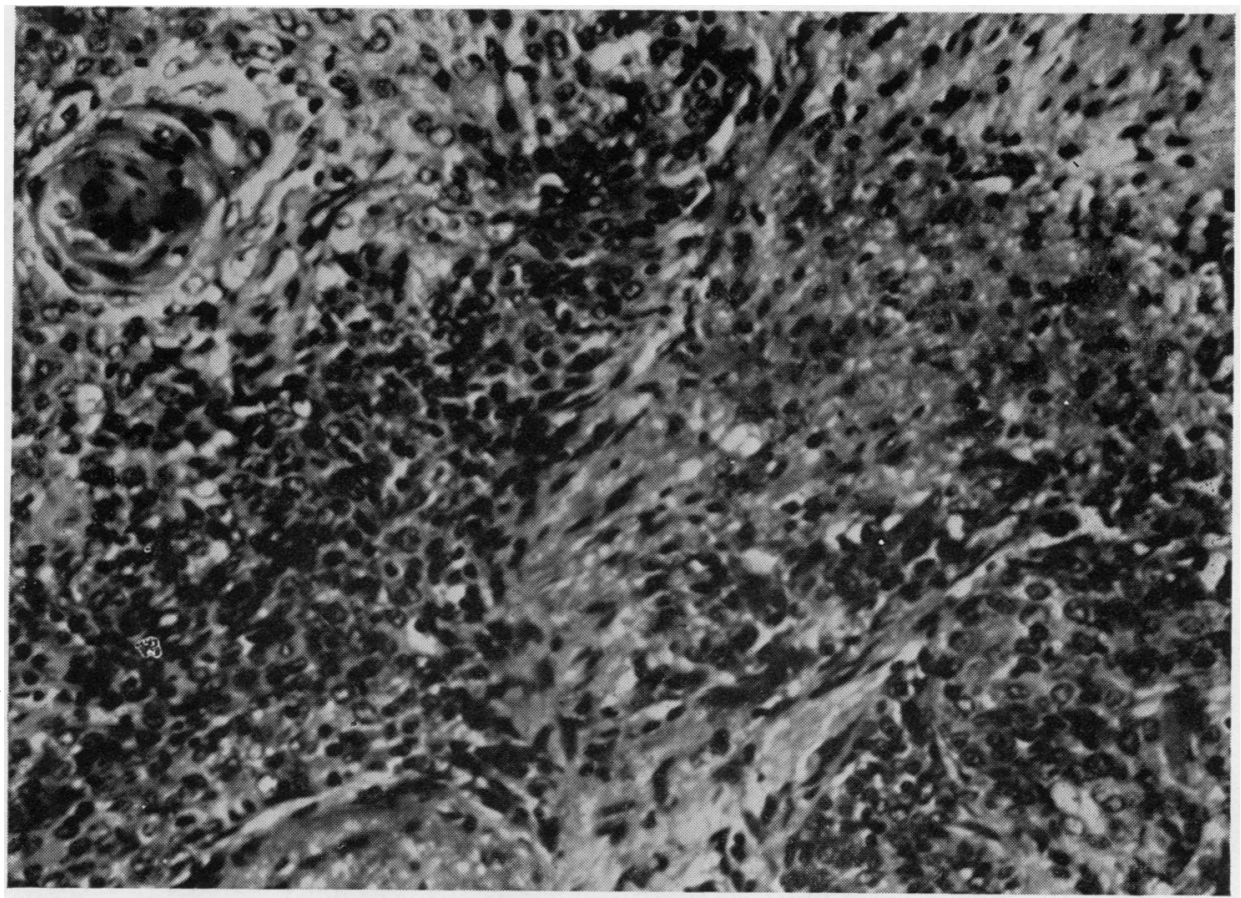

FIG. 9. Anaplastic 'small cell' basaloid carcinoma. Haematoxylin and eosin $\times 200$.

nodes involved; two developed inguinal node involvement only.

HISTOLOGY AND LYMPHATIC SPREAD The histology of the lymph node metastases was generally similar in all cases to the appearance in the primary tumours. The distribution of the three histological grades of malignancy among the 14 cases who had lymph-node metastases was as follows: four were well differentiated, four moderately differentiated, and six anaplastic basaloids.

\section{RESULTS OF TREATMENT}

RADIOTHERAPY Six patients were treated by insertion of radium needles or by radiotherapy only because of poor general health or extensive disease which was surgically inoperable. None survived five years. Of four patients with anaplastic basaloid carcinomas, three were dead from their disease within 18 months and one survived for three years. Two patients had moderately differentiated basaloid tumours; one died one year after treatment and the other survived for nearly three years before dying of recurrence.

LOCAL EXCISION Three patients were treated by local removal of the primary tumour. All had basal- oid tumours of a moderately differentiated type. One died three years after the local excision, which was considered palliative because of involved inguinal glands. A second patient is still alive one year after operation followed by radiotherapy. The third patient is alive eight years after local excision for a small tumour lying just above the dentate line.

EXCISION OF RECTUM AND ANAL CANAL Twenty-seven of the 36 patients in this series were treated by excision of the rectum and anal region. There were three post-operative deaths and one patient has been lost to follow-up. Three are still alive and well less than five years from the time of operation leaving 20 cases available for a study of the relationship between pathology and prognosis (Table I).

Eleven of 20 patients $(55 \%)$ have survived more than five years after excision of the rectum, and five of these lived more than 10 years after operation. All but one of these five had well-differentiated basaloid tumours, the other having had a moderately differentiated tumour. Three had lymph node metastases in the haemorrhoidal glands of the operation specimen. Of those nine cases dying before five years, eight definitely died of recurrence and one of a primary carcinoma of the bronchus. Among the eight who died of recurrence there were five with anaplastic basaloid carcinoma, two with 
TABLE I

BASALOID CARCINOMA TREATED BY EXCISION OF RECTUM WITH ADEQUATE FOLLOW-UP

Lymph Node Metastases Prognosis

Sex Age $\begin{aligned} & \text { Haemor- Inguinal } \\ & \text { rhoidal }\end{aligned}$

\begin{tabular}{llll}
\hline \multicolumn{3}{c}{ Group I: well } & differentiated \\
M & 53 & + & \\
M & 58 & + & \\
M & 71 & + & \\
F & 43 & - & \\
F & 56 & - & \\
F & 67 & - & \\
F & 53 & - & - \\
M & 54 & - & \\
M & 62 & - &
\end{tabular}

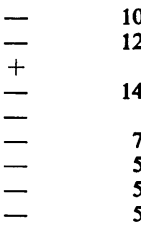

Group II: moderately differentiated

$\begin{array}{lll}\text { F } & \mathbf{4 8} & + \\ \mathbf{F} & \mathbf{4 6} & + \\ \mathbf{M} & \mathbf{4 5} & + \\ \mathbf{F} & \mathbf{6 4} & - \\ \mathbf{F} & \mathbf{5 4} & -\end{array}$

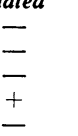

10

14

2

Group III: poorly differentiated and anaplastic

$\begin{array}{lllll}\mathbf{M} & \mathbf{5 8} & + & - & 2 \\ \mathbf{M} & 69 & + & + & 2 \\ \mathbf{M} & 71 & - & + & 2 \\ \mathbf{M} & \mathbf{7 2} & - & - & 2 \\ \mathbf{M} & 63 & - & - & 2 \\ \mathbf{M} & \mathbf{4 9} & - & - & 1\end{array}$

moderately differentiated tumours, and one with a well-differentiated carcinoma. The three patients with differentiated growths had extensive involvement of regional lymphatic glands in the operation specimen.

LYMPHATIC SPREAD AND PROGNOSIS The prognosis for patients treated by excision of the rectum with and without lymph node involvement has been compared. There were 10 patients with involvement of regional glands six of whom had haemorrhoidal node involvement only; two had both haemorrhoidal and inguinal node involvement and two inguinal gland metastases only. The five-year survival rate of the whole group was four out of 10 cases $(40 \%)$. The four who survived have all remained alive for 10 years since operation. None had inguinal node metastasis, whereas all four patients who had inguinal node involvement died within two years of operation. It has previously been shown (Morson, 1960) that the inguinal gland direction of spread is an indication of advanced disease that is most unlikely to be cured by surgical treatment.

Among the four patients with lymphatic metastases who survived two had well-differentiated tumours and two moderately differentiated. There were three anaplastic basaloids, two moderately differentiated basaloids, and one well-differentiated tumour among those six patients who died of recurrence. The only patient with well-differentiated basaloid who died of recurrence was an advanced case with both haemorrhoidal and inguinal nodes involved at the time of operation.

Seven out of 10 patients without lymph node metastases survived five years after excision of the rectum $(70 \%)$. None of these has yet shown any signs of recurrence and two have now survived for more than 10 years. Six of the seven tumours were well-differentiated and one moderately differentiated. The three patients who died all had anaplastic basaloid tumours.

HISTOLOGY AND PROGNOSIS The 20 patients treated by excision of the rectum who survived operation and for whom accurate follow-up information was available have been subdivided according to the three grades of malignancy of basaloid carcinomas. The prognosis for these three grades is: for welldifferentiated basaloid carcinoma the five-year survival rate is eight out of nine cases (nearly $90 \%$ ); for the moderately differentiated tumours it was three out of five patients $(60 \%)$; and for the six undifferentiated (anaplastic) basaloid carcinomas there were no five-year survivors.

\section{DISCUSSION}

Squamous carcinoma of the anal canal is uncommon, accounting for only about $3.7 \%$ of all carcinomas of the rectum and anal region. Approximately one in five squamous carcinomas of the anal canal in our material are of the basaloid type which makes the latter a relatively rare tumour. Lone et al. (1960) gave an identical frequency for basaloid tumours, but also stated that almost half of all anal cancers contain some areas resembling basal cell carcinoma of the skin. This is a much higher estimate than our studies indicate.

Basaloid tumours characteristically arise from the entodermal-ectodermal junctional zone (cloacogenic zone) of the upper anal canal. This is also the characteristic location for the majority of squamous cell carcinomas of the anal region (Morson, 1960). The predilection of basaloid tumours for this zone is a reflection of its inherent epithelial instability (Walls, 1958) which is a feature of many junctional zones throughout the body. This explains the variety of histological growth patterns seen in anal cancer. The term 'cloacogenic' has stemmed from the work of Herrmann and Desfosses (1880) who considered that the zone is a remnant of the cloaca. In fact it is only one derivative of the cloaca (Tucker and Hellwig, 1935), no more so than, for example, the urinary bladder. The zone is certainly the site of the entodermal-ectodermal junction and it is for this reason that we prefer the term 'junctional' to describe it. 
It was not found possible from the study of our basaloid cancers to get a complete picture of their histogenesis. However, from the material available, it would appear that basaloid carcinomas arise from proliferation of basal cells of simple non-keratinizing squamous epithelium. The other types of epithelium in the junctional zone, stratified columnar and transitional epithelium similar to that found in the urinary tract, often show squamous metaplasia. Moreover, some of the peculiarities in the histology of basaloid tumours, such as the formation of small acini and a tendency to a papillary growth pattern resembling transitional cell carcinoma of the bladder, may well be explained by the presence of these different types of epithelium normally present in the junctional zone.

The concept of basaloid carcinoma of the anal canal is useful for two main reasons. First, it draws attention to a histological variant of squamous cell carcinoma of this region which, excluding the anaplastic basaloids, has a good prognosis. Secondly, it makes a distinction from true basal cell carcinoma of the peri-anal skin with which it is sometimes confused. It must be emphasized that basaloid carcinoma is a potentially metastasizing tumour of the anal canal whereas basal cell carcinoma, in this context, is a non-metastasizing tumour of the hair-bearing skin around the anus. Occasionally, true basal cell carcinomas involve the anal canal by upward spread.

The histological feature which most distinguishes basaloid carcinoma is the presence of palisading of nuclei at the periphery of the clumps of tumour cells. If this is present then it is indicative of a good prognosis even though lymphatic metastasis has already taken place as judged by examination of the operation specimen. Lone et al. (1960) noted that in 'non-lethal' cancers of the anal canal basaloid elements predominated. Thackray (1951) showed that palisading was a well-marked feature in those rodent ulcers reacting favourably to radiotherapy but found that only the extent to which growth appeared infiltrative seemed to have a direct bearing on prognosis. In our basaloid tumours of the anal canal the presence of palisading and the relative absence of infiltration are likely to be associated with a good prognosis.

An attempt has been made to grade basaloid tumours according to the presence or absence of palisading and other features, including their cytological characteristics. The method is justified by the results which show that the prognosis is very good $(90 \%$ with five-year survival) in cases of welldifferentiated basaloid tumours even when lymphatic metastasis has already occurred. In cases of moderately differentiated basaloids the five-year survival rate of $60 \%$ is still considerably better than the survival for all squamous cell carcinomas of the anal canal. The anaplastic basaloids, on the other hand, show an extremely poor prognosis even when lymphatic metastases are absent. Wittoesch et al. (1957) commented on the poor prognosis of their 'small cell' or anaplastic basaloid tumours.

The presence of lymphatic metastases has a profound influence on the prognosis of basaloid tumours as a whole. This is to be expected. If, however, the anaplastic basaloids are excluded then lymph node involvement has a much less adverse effect on prognosis as evidenced by the fact that four cases of differentiated basaloids with involved lymph nodes (two of group I and two of group II) are still alive 10 years after excision of the rectum.

Our studies indicate that patients with basaloid carcinomas of the anal canal should be treated by excision of the rectum. The one case treated by local excision which appears to have been cured was a small tumour with invasion of the submucosal tissues only. This suggests that local excision can be the treatment of choice provided the tumour is small, well-differentiated, and accessible to adequate local removal.

We wish to thank Dr. A. C. Thackray of the BlandSutton Institute of Pathology of the Middlesex Hospital for his help; also Mr. Norman Mackie for the photographs and Mr. Lloyd Soodeen for technical assistance. This investigation was supported by grants to Dr. Lillian S. C. Pang from the Medical Research Council and to Dr. B. C. Morson from the British Empire Cancer Campaign for Research.

\section{REFERENCES}

Herrmann, G., and Desfosses, L. (1880). C.R. Acad. Sci. (Paris), 90, 1301.

Lone, F., Berg, J. W., and Stearns, M. W., Jr. (1960). Cancer (Philad.), $13,907$.

Morson, B. C. (1960). Proc. roy. Soc. Med., 53, 416.

—, and Volkstädt, H. (1963a). J. clin. Path., 16, 200.

- —- (1963b). Ibid., 16, 126.

Thackray, A. C. (1951). Brit. J. Cancer, 5, 213.

Tucker, C. C., and Hellwig, C. A. (1935). Arch. Surg., 31, 521.

Walls, E. W. (1958). Brit. J. Surg., 45, 504.

Wittoesch, J. H., Woolner, L. B., and Jackman, R. J. (1957). Surg. Gynec. Obstet., 104, 75. 